\section{Can GM marmoset use be justified?}

We question the premise that genetically modified (GM) marmosets are essential to Japan's brain-mapping project for studying disorders such as schizophrenia and depression (Nature 514, 151-152; 2014). It runs counter to efforts in fields such as toxicology to reduce or eliminate the use of non-human primates in research.

Our conclusions in the 2011 Review of Research Using NonHuman Primates (see go.nature. com/kgy27w), which included UK neuroscience research between 1997 and 2006, are relevant here. The review judged such research to be of high quality, yet few projects showed evidence of biomedical benefit - despite being completed many years before the review.

There was a tendency among researchers to make overoptimistic and unsubstantiated claims for their work and how it might improve the treatment of brain disorders, presumably to strengthen their case for funding. We concluded that "the size of the problem to which the science relates should not be accepted as sole justification for individual items of research" and that "health benefits should only be claimed when their potential is real". In some instances, we judged that the case for using non-human primates - rather than other species, including humans - was not well made.

It could be argued that the unavailability of suitable GM animals at the time might account for the poor translation into health benefits. But the justification for using GM marmosets in research today needs to be much stronger, because of the substantial ethical and welfare issues at stake.

You quote US neuroscientist Terry Sejnowski, who proposes consideration of "the ethical issues that will inevitably arise up the road". We contend that these should be considered before the journey starts.

Patrick Bateson Cambridge, UK.

C. Ian Ragan London, UK. ian.ragan1@btinternet.com

\section{Sustainability: call to coordinate actions}

The first step in implementing the United Nations' Sustainable Development Goals (SDGs; see M. Stafford-Smith Nature 513,$281 ; 2014$ ) will be to identify critical nodes at which issues such as water, energy and food need to be addressed simultaneously and that have the potential to set the agenda.

For example, schools could play a part in increasing water, food and energy security by improving students' knowledge of these systems as well as of flood and drought responses. These nodes could help to coordinate existing discussion structures into new national and local forums, and to overcome bureaucratic silos.

Contribution by governments to the SDGs will be voluntary, so efforts should focus on increasing the numbers of organizations, people and networks that can be linked to the SDG governance system. This would allow the system to address inequities in gender, geographic location and ethnicity, for example, at regional, national and local scales.

Effective monitoring will be pivotal to the success of the SDGs. If done globally through existing $\mathrm{UN}$ agencies, there is a risk that key resources would be diverted, whereas monitoring by individual countries might be inadequate or inconsistent. The UN Highlevel Political Forum could have an important role, but people outside the current sustainability discussions need to be heard as well. They too can help to craft context-specific goals and targets, maintain ambition and develop complex monitoring capacity.

Norichika Kanie Tokyo Institute of Technology, Japan.

Casey Stevens Providence College, Rhode Island, USA. kanie@valdes.titech.ac.jp

\section{Exempt green tech from trade rules}

Next year in Paris, parties to the UN Framework Convention on Climate Change have the task of developing a global agreement to reduce carbon emissions - a successor to the failed Kyoto Protocol. They should strike a grand bargain with the World Trade Organization (WTO) to promote green industry.

For example, the new protocol could draw up an open-ended list of products and processes that would reduce emissions. This could then be used to exempt countries from the rules of fair trade for, say, five years, to allow them to build green industries.

Trade in green industries is crucial for transforming fossilfuelled economies. Countries trying to promote a green economy should not have to experience trade disputes (see, for instance, go.nature.com/7joyyk).

There is a precedent for such exemptions in the WTO's General Agreement on Tariffs and Trade. The negotiation of a new 'Paris Protocol' provides a once-in-ageneration chance to create green industries and to cut emissions. John A. Mathews Macquarie University, Sydney, Australia. john.mathews@mgsm.edu.au

\section{Engage more cohort patients in research}

Input from patients and the public is a requirement for funding by the UK National Institute of Health Research (NIHR), but is met by scepticism from some academics.

We analysed 70 birth cohort studies to evaluate the basis of this scepticism (P. J. Lucas et al. BMC Med. Res. Methodol. 13, 56; 2013). Such studies rely on recruiting and retaining many people over many years - often a challenge. Retention was a factor in the June decision to pause the US National Children's Study, for example (see go.nature.com/mfmhhr).

These problems might be overcome by consulting participants about research design and processes, rather than using them solely for data provision. But we found very few examples. Some scientists feared that involving participants could compromise data integrity; others lacked the right resources or were ignorant of the practice.

There is much to be gained from engaging participants in research, but persuading academics to do so will require better support and for other funders to follow the NIHR's lead. Patricia Lucas, Maggie Leggett University of Bristol, UK. Simon Denegri NIHR, London. maggie.leggett@bristol.ac.uk

\section{Translating public action into policy}

Last month, millions took to the streets in climate rallies organized by some 1,500 organizations in 158 countries. Their message: that world leaders at the United Nations Climate Summit in New York must tackle the challenges of global warming head on. However, it is by no means clear that this will translate into firm political pledges (see Nature http://doi.org/v3c; 2014).

For instance, 80,000 people demonstrated ahead of the UN Climate Change Conference in Copenhagen in 2009. At the meeting, a political collusion between the United States and a group formed by Brazil, South Africa, India and China ended up sidelining the countries most in need of action against climate change (see A. P. Kythreotis Prog. Hum. Geog. 36, 457-474; 2012).

When it comes to crucial issues of social justice and the economy, politicians should be guided by the people they are supposed to serve (see A. Petherick Nature Clim. Change 4, 81-83; 2014). Chrystal Mantyka-Pringle University of Saskatchewan, Saskatoon, Canada.

Andrew P. Kythreotis Cardiff

University, UK.

c.mantyka-pringle@usask.ca 